\title{
Harassing The Mentors: A Phenomenological Study In Cross Gender Perspective
}

\author{
Zaeema Asrar \\ Department of Commerce \\ University of Karachi \\ Syed Waqas Hussain \\ Department of Management Sciences \\ Shaheed Zulfiqar Ali Bhutto Institute of Science \& Technology, Karachi \\ Muhammad Mubeen \\ Department of Management \\ Bilkent University, Turkey
}

\begin{abstract}
The phenomenon of sexual harassment in an educational setup has been an unpinned topic. With more than $47 \%$ of the teaching staff in educational institutions females, the situation is getting worst on the esteem and honour of the profession. The nobles of the profession are on the target of harassment by none other than their own students. This paper explores particular type of sexual harassment in an attempt to understand and apprehend the essence, meanings and elements of the sexual harassment caused by male students towards their female teachers in a formal education environment. The research strategy is based on interpretive consumer research, with influences from phenomenology. The main research data was generated by face-to-face interviews from five female secondary and higher secondary teacher about their experiences of facing sexually harassing behaviours in the course of class and school. This study theoretically contributes by exploring the breadth of the issue faced by teachers and explored the defining terms, elements, reasons and responses and measure taken by the interviewed teachers.
\end{abstract}

Keywords: Sexual Harassment, Harassing the Teachers, Students Harassing Faculty.

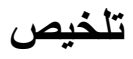

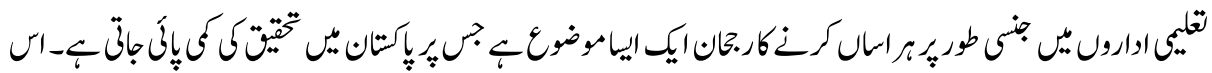

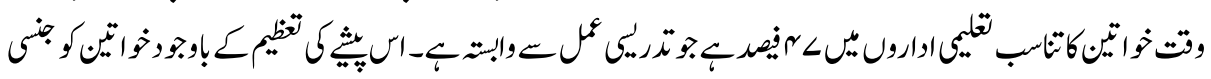

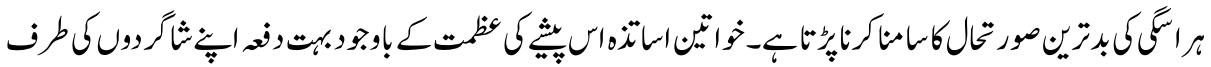

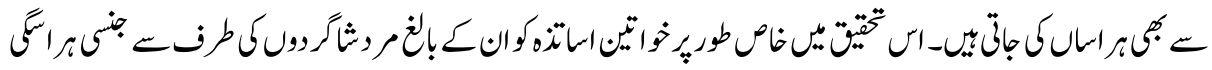

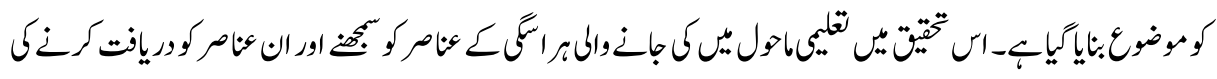




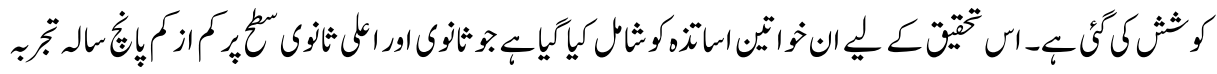

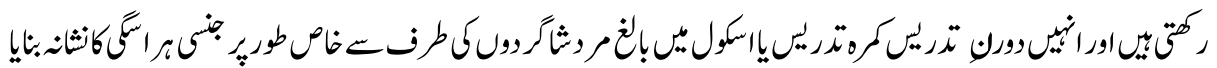

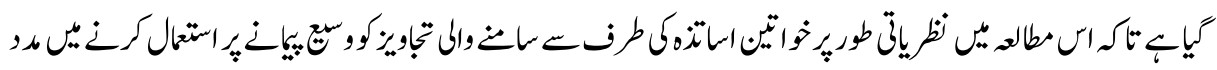

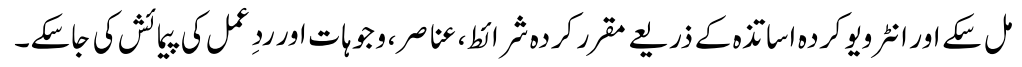

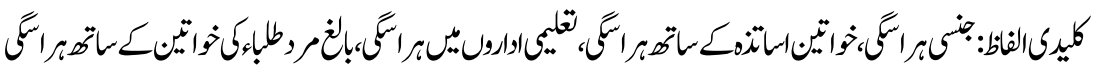

\section{Introduction}

According to UNESCO (2013) almost 1.4 million people are attached to profession of teaching, be it through formal or non-formal delivery system in Pakistan. Teaching is considered to be the noblest of the professions world-wide, and teachers are termed as "Social engineers of the 21st century". According to UNESCO report (2013) almost 47\% of the teaching staff in different levels of education throughout Pakistan is female. Teaching due to its nobility and lesser working hours is the most favoured choice among individuals (females) and their families when it comes to working. Pakistan is ranked 6th in world most populous countries as per the world population forum.

However, despite of its nobility, graciousness and civility teachers have to deal with difficult students who through their actions, gestures, comments and other verbal and nonverbal communications make them uncomfortable and in some extreme cases harass them. The exhibition ensues on a continuum of a lesser offensive behaviour like chasing and calling with different names or by talking subliminally to an aggressive level of touching and holding. Sexual harassment is culturally and socially based construct which is deeply embedded in dimensions of sexuality, gender and power. Sexual harassment has been explored, defined and explained by many scholars with the perspective of education where students are the victims. Teaching which has been considered and termed as a noble relation between teacher and student has been jeopardized due to ill mindedness and sickening thoughts, sights, comments and gestures of male students. The incidents where teachers are harassed go unreported most of the time as the instructors/ mentors/ facilitators facing such a behaviour are reluctant to share it with peer or higher authorities or even families. Such individuals are more concerned about their financial conditions and social image than the harassment or the ill treatment. Moreover, the norm of blaming the harassed person as the responsible and the sole guardian of their respect and integrity also diminishes the chances of such incidents being reported at early stage which due to obliviousness generate into much bigger problems and a societal issue.

The sexual harassment is defined in different terms, but it is primarily linked with the unwanted, unwelcomed and unsolicited sexual conducts and actions of male individuals. 
Researchers believe that such an action or conduct is the resultant of discriminatory societal system and culture. Schools, institutions and cultural settings are the main players in the construction of ideas of gender differences. The dichotomy of gender is well embedded through different practices during the school regime and many researchers argue that due to lack of attention given to male students they fall for the trap of ill thinking and behaviours which as not addressed at earlier age, leads to severe conditions of active harassing of peer students or even the teachers.

\section{Statement of the Problem}

Recently, there are a number of cases of harassment on daily basis which goes unreported in education system. Teachers due to shame, self-respect and their image tend to ignore the unethical actions, gestures, activities and comments of students which are harassing to teachers. These harassing gestures and statements cause sheer demotivation and demoralization of the teachers. There have been numerous studies conducted on the subject of harassment, sexuality and gender but harassment that women teachers face while dealing with adult male students is still an unmapped area/topic/phenomenon in case of Pakistan's education perspective. Therefore, it is necessary to understand and analyze through the enliven experiences of women teachers how harassment is defined and understood and what interpretations do the women teachers associate with them.

\section{Purpose of the Study}

The purpose of this phenomenological study was to explore and understand the essence and broader definition of the term harassment as experienced, understood and implied by women teachers dealing with male adult students in a setting of secondary and higher secondary education system.

\section{The Research Questions}

The intent of the research question was to contract the purpose to one or several question that address the essence of the study. To explore the phenomenon of women teachers being harassed by students in an official setting of education system, the overacrching ideas were condensed or reduced to the following questions.

1. What meaning do women teachers serving in secondary or higher secondary formal educational institution ascribe to sexual harassment based in their lived experience?

2. What are the elements of sexual harassment according to women teachers?

3. What the essence of sexual harassment is as understood, experienced and ascribed by the women teachers? 


\section{Literature Review}

\section{Conceptualizing Sexual Harassment}

Sexual harassment is one of the widely explored and studied topics in both public and private sector due to its consequences on the well-being of the individual, psychologically and health wise (Shneider, Swan, Fitzgerald, 1999). Before this topic was explored and widely studied, it was virtually unknown in the scientific literature (Brogida \& Fiske, 1995). Recently the popularity has increased of sexual harassment of women as a topic of research and organizational management.

For ages sexual harassment of women as a topic was considered taboo even to discuss. Many define sexual harassment differently depending on their own approach. Tengku Omar and Maimunah have defined sexual harassment as an action that is not accepted and favoured and is done without the consent of the victim, an action can be in form of verbal, non-verbal, visual or physical (Tengku Omar \& Maimunah, 2000, "Workshop on Code, 1999"). Sexual harassment can have different impact on different individual or job status; or receiver can feel threatened that his or her personal space has been invaded without consent by a sexual act (Ministry of Human Resources, 1999; Tengku Omar \& Maimunah, 2000).

Researchers avoid using explicit theoretical perspectives to describe the incidence or various types of sexual harassment at schools and colleges; numerous of theories are identified on biological, developmental, pathological, abuse of power and cultural levels (Lee et al., 1996). Among all of the theories identified, only the abuse of power and the cultural offers a degree of credibility when applied to empirical research on sexual harassment (Lee et al., 1996; Stein et al., 1993). Braithwareet. Al believes that easy and free access to internet and on it easy access to pornographic sites are corrupting and polluting the growing adult minds. Researchers have added the theories after above mentioned ones, the impact of pornography and sexual scripts on the emerging adults (Braithware et al., 2015).

\section{Biological Theory}

Hormonal imbalance and different body sizes and features make male more militant than females. Biological theorists believe such assertiveness in males often cause males to be seen as the perpetuators and females as victims of assault or sexual harassment (Bourne et. al, 2015). 


\title{
Developmental Theory
}

In such technically equipped era people communicate their feelings through social interactions through different mediums specially internet and social sites (Lindsey, 2015). Young males and females find it difficult to gage whether they take sexual attractions positively or negatively. Inability to express the feelings leads to indulgence in harassing activities (Masten, 2014).

\section{Pathological theory}

Victim of harassment undergoes through trauma causes individuals to become less tolerant, sympathetic and in extreme cases they turn to take revenge by indulging in similar hurtful behaviours as they have experienced (Dobry, Braquehais \& Sher, 2013). Sexual harassment is an antisocial form of behaviour in views of pathologists.

\begin{abstract}
Abuse of Power
In context of abuse of power three different concepts share a common view of sexual mechanism which leads males to gain dominance over females. Sexual harassment done based on abuse of organizational power is the most common view and the first conceptualization under the abuse of power theory. Here, depending on roles, individuals are seen as having differing amount of power in organizations (Mubin et al, 2014). Typically, males occupy most powerful positions in organizations, have opportunity to abuse that authority. Females can equally be responsible for such abuse under above mentioned conceptualization (Kanter, 1977).
\end{abstract}

Sexual harassment is a form of exclusionary intimidation as well, under second view. People who usually treat others with kindness can resort in indulgence in harassment when conditions are changed, or posed a threat to societal privilege.

In society male dominancy over females leads to the third view of sexual harassment in context of abuse of power that is abuse of societal power. Expounder of this theory point to sexual harassment of adult female teachers by adolescent male students, middle class women on street by male construction workers, female doctor by male patients as examples of primacy of gender hierarchy of the sexes (e.g., MacKinnon, 1979; 1993).

\section{Mentorship and Sexual Harassment}

Robinson, K. (2000), in her phenomenological study, "Great Tits, Miss!'The silencing of male students' sexual harassment of female teachers in secondary schools": A focus on gendered authority" took the perspective that the cases of sexual harassment where teachers are the victims of students harassing them is increasing every day(Akber et al (2014). Little or no attention has been given to this phenomenon where female teachers 
are sexually assaulted or threatened by their male students resulting in women defending their claims of harassment.

The following research under study has taken the perspective of Robbin, K (2000) and desires to study the elements of sexual harassment along with power authority that alters this relation and result in harassment of teachers. However, the study takes into account the breadth of the sexual harassment faced by female teachers and try to explore the phenomenon through the eyes of the teachers who have enliven experience of being sexually harassed by their students. The theoretical addition this paper is going to make is the identification or elements, responses of the teachers and measures they take when being caught in such a situation. This study will also put down the stone to understand the different behaviours and attributes teachers attach with defining sexual harassment and what conducts are considered as harassing in their eyes.

\section{Methodology}

This study is epistemologically based on the concepts of constructivism which will take on the theoretical perspective of interpretivism. The phenomenological methodology will be implied where the data will be collected through in depth interviews with the women teachers of secondary and higher secondary school.

\section{Data collection Procedure}

The data has been collected from secondary and higher secondary female teachers who have enliven experience of being harassed by the adult male students during the formal setting of school or college. The respondents were interviewed in depth where they shared their experience about the incidents and feelings of being sexually harassed by their own students in a setting of a formal educational institution. The respondents were prompted and probed by using un-structured questionnaire.

\section{Data analysis Procedure}

Building on the statements and quotations recorded from the respondents against the central research questions, the significant statements, sentences and quotes were highlighted which provided better understanding of how participants have experienced the phenomenon. The experiences and the meaning implied by the respondents were transcribed. Verbatim of the respondents were transcribed in black and white. The choice of verbatim was made to incorporate all the relevant information regarding the interview. The researcher deliberately made the choice to record long 2 hours of interviews to get 
hold of the core of the concern and issues related to the topic. Despite in the initial plan, consent was taken from all the potential respondents about recording the interviews on video, the respondents were not comfortable and refused to carry on with the interviews with this modes of recording.

The theoretical underpinning of interpretive phenomenological analysis is double hermeneutics, therefore the transcribed data from the respondents was analyzed by reducing the experience statements into themes to come up with the textual and structural description of the experiences of the women teachers. From these themes, essence of experience were extracted and reported.

\section{Generating Data}

The data generation was carried out by interviewing the selected potential respondents. But, first we wanted to know about the general concept of sexual harassment for which we underwent excessive exploration of the literature. Then started with interviewing the purposefully selected respondents for capturing the enliven experiences of teachers facing sexual harassment in formal educational environment from adult male students. The data gathered from the respondents were through personal face to face interviews using unstructured questionnaire as a guiding script.

\section{Recruitment Process and Research Setting}

The recruitment of the interviewees was carried out with the help of a few friends. Post was circulated over social networking sites requesting to share the contacts of the persons who have faced the phenomenon or to volunteer themselves if they are the victims. People were initially reluctant and were not replying to the post. Then it decided to personally message the known faculties (among personal and professional contacts) of different colleges and school. They were hesitant about the topic and their anonymity. Upon ensuring the complete anonymity about their profile and their affiliation, they agreed to meet in person over a lunch.

The participants were invited to a porche fine dine restaurant where a single table with two chairs were purposefully set up in a hall with no other table. The reason for the selection of the restaurant was the non-availability of a calm place, as they did not want to discuss this at their working place or their residence. In order to comfort them the small floor was booked and all the unnecessary stuff were removed. The participants felt calm and cosy seeing the adjustment and appreciated the effort made to accommodate them. The respondents felt special and started to take things seriously about the interview after entering into the interview setting. The respondents ordered from the list of their favourite cuisine and after initial chip chap the interview started according to the planned protocol. 


\section{Personal Face to Face Interviews}

The interview protocol was designed in the light of objective and research questions of the study. The questionnaire contained three broad horizons that were to be covered. The first couple of questions were directed towards understanding the broader definition of the term sexual harassment as understood by the female teachers. The later couple of questions were aimed towards understanding of the essence of sexual harassment in the light of the enliven experience of the teachers. With essence, I meant to understand the depth of the experience that teachers had using "what and why" type of questions. The last part of the protocol covered the elements/tool/actions/gestures of sexually harassing conduct as understood and faced by these teachers.

\section{Profile of the Interviewees (Participants)}

Respondent 1: Miss HH belongs to a lower middle class family, where personal respect, esteem and education are given more importance and weight age than any other aspect of life. Miss HH is currently 25 years of age and started teaching 5 years ago when she was just 20, about to complete her bachelors from University of Karachi. The reason behind the early starting of teaching career was that she wanted to earn pocket money and gather enough cash to support her dream of completing her masters in mathematics after gold medal in bachelors of mathematics. Miss HH has one elder brother, and her father passed away 4 years ago after a couple of months' ailment.

Respondent 2: Ms. NO is $\mathrm{PhD}$ in Urdu, a known literary researcher and scholar. She completed her PhD. from university of Karachi. She has a vast experience of around 15 years of teaching and educational management. She is a working mother and have 2 kids, one of them is in 8th grade while the younger one is in nursery class. She started teaching as a hobby which after marriage became a necessity to support the family expenses. Ms. NO has a graceful personality and it is almost impossible that you don't get impressed.

Respondent 3: Miss RY belongs to an upper middle class family. She is married and has a kid who is three years of age now. She started teaching in a school at the age of 22 after completing her Bachelors in Arts from University of Karachi. She defines her personality as a "social freak" and have many friends. She is an outgoing impulsive person. She likes socialising and do not shy away from the male gender. She is an outspoken and loud person with a high self-esteem. She started working in a school to pass her leisure time before she would get married. She was already engaged when she started working and was only counting days as the teacher. Miss RY is a talkative person and often misunderstood and mis-qued for her nice and jolly behaviour. Miss RY has an attractive personality and like to dress up in the most presentable manner. She believes that life is about eating and dressing up. 
Respondent 4: Miss Sid belongs to a middle class, started working at the earlier age. She is in teaching profession since 6 years and her first job was in a school when she was studying in her intermediate. She started working to earn pocket money and also to contribute to her educational expenses. She has done her BSc from University of Karachi. She is a bright teacher with a lot of charm and charisma.

Respondent 5: Miss SN, belongs to a lower middle class family, living at PIB colony. She has two sisters and a brother, where father and brother are the bread earners. Miss SN started working around 9 years ago, as an escape from the family suppression and boredom. She belongs to a family where sending females for higher education is prohibited. Miss SN, after her intermediate education completed her bachelors as a private candidate. In order to keep herself busy and to stay active she started working at a local coaching centre near her house which was owned by one of their fathers' closest friends. This was the first time any of the female started working and earning. For Miss SN it was more than just a job, it was a way to keep herself at par from the daily scuffles and brawls which kept irritating her. She used to find peace outside home and preferred spending most of her time outside home at work.

\section{Role of the Researchers}

The main researcher SWH of the study is associated with education industry for last 7 years and held important positions such as Coordinator and Trainer at degree awarding institutes, coordinator student affairs. The other two co-researcher ZA and MM have been associated with education industry since 2000. SWH has the position of Principal at a higher secondary school and college. Researcher ZA has the Chairperson and HOD position of Department of Commerce, University of Karachi. Researcher MM has been the co-ordinator Evening Program - Faculty of Commerce, Economics and Business Administration, FUUAST, AH Campus and currently graduate scholar abroad doing M.Phil leading to Phd on HEC-Pakistan Scholarship. All the researchers have come across numerous situations where teachers reported unethical and immoral acts of students during the class hours or in the formal setting of school and college. The continuum of the actions ranges from avoidable situations to extremely disrespectful ones. The majority of the reported events occurred with young female teachers where verbal and visual discourses were the primary forms of harassment. Despite of the fact that in a teacher-student relation, the teacher holds more power, the teachers feel weak and fragile in such situations. The women teachers are afraid and terrified to openly report such events, fearing that they will be misjudged, ridiculed or mocked by the peers, authorities and other actors of society. The Main researchers have iterated the study through unstructured questionnaire and co-researcher along with main researcher have analysed, understood and reported the themes which according to the sample women teachers are the defining terms of sexual harassment in a formal educational environment. 


\section{Data Analysis and Discussion}

To carry out the analysis, a four phase logical process was adopted. In the first phase of analysis, we read and reread the transcripts which is known as naïve reading, with the aim to grasp basic understanding of the basic interview as a whole. We highlighted and underlined the lines which were of interest and importance and wrote remarks as part of memo writing to depict and reflect upon our understanding about the interview. In second phase we wrote the individual summaries of the interviews and their descriptions. The purpose of writing the summaries was to understand the interviews in totality in view of the background of the informant/participant, to precisely cover the initial thoughts about emerging themes.

In third phase of data analysis, definitions and essence of sexual harassment started emerging through coding, categorization, and thematization of the data. We started with more than 30 emerging codes which were filtered and sorted to become 18 nonoverlapping and non-redundant categories which were combined to form themes of the analytical framework.

In the fourth and the final phase we interpreted the evolving ideas based on our in-depth understanding of the sexual harassment developed from the interviews of the respondents. While interpreting the data, we tried to be less judgmental and avoid any biasness due to our gender and stay true to the phenomenon.

\section{Defining Sexual Harassment}

While interpreting the data and categorization, we realised that many emerging ideas could be binned into one larger theme for the better understanding and representation of a consolidated definition. The term sexual harassment is defined as the unwanted and unsolicited sexual attention through verbal or non-verbal actions which makes a person feel disgusted, objectified, threatened, assaulted and shaming of being a woman and gestures which are impropriety in nature.

Any behaviour or gesture that students make which give you a disgusted feel of being a whore/a prostitute, an object of use or an object on sell, an action which makes you feel annoyed and disrespected is harassment or more specifically sexual harassment.

Miss $\mathrm{HH}$, Interview from field data

In my opinion, sexual harassment is any activity movement, gesture, or action that makes you feel uncomfortable, shaming about being woman, gives you a feel of a mere object, makes you feel weak and helpless and physically assaulted. 
I will say, any action or conduct which gives a sensation of being sexually disturbed, distressed and anxious is called sexual harassment.

Ms. NO, Interview from field data

Sexual harassment is not particularly bounded to physical assault and physical molesting, a gaze filled with lust and hunger is also a harassing gesture. Students at times loom up to feel the breath and air of the teachers and comment on their scents and colognes. These metaphorical actions at times go unaddressed as teachers think of it as their misjudgment or misinterpretation of intention of students. Most of the women select this profession due to its nobility, and therefore anything against the prestige and honour which makes them feel sexually conscious is counted as harassment. Harassment in its broader terms are related to making the other person cognizant by gender. The students tend to loom-up and try to get into as closer proximity as possible.

But the students at times gives you a very strong feel of you being a different gender. They misgauge your avoiding behaviour as a weakness and tend to cross their limits. Crossing my personal-space, touching me or intending to touch me, sending me vulgar or inappropriate contents over facebook or whatsapp or through messages

Ms. NO, Interview from field data

Another wave of sexual harassment identified or recognized is sending vulgar texts, videos and other stuff over social contact points and mobile phones. The students also manage to get numbers and tease and torture teachers by late night calls and pranks.

Calling me at night over my mobile number, threatening or attempting to frighten me or making me feel ashamed about myself. $\quad$ Ms. NO, Interview from field data

Students filter your every inch in a desperate attempt to get a glimpse or even a slightest view of the outline of your clothes. They whistle on your face and complement your dressing in a manner that gives you a feel of standing nude in front of them.

Ms. RY, Interview from field data

A feel of being a whore/a prostitute, an object of use or an object on sell

Miss $\mathrm{HH}$, Interview from field data

Adult male students not only verbally assault the female teachers, they also try looming up and desperately reaching to rub and touch the teachers. Usually they try it in a manner which can easily be manifested as an accident rather an actual physical assault. They start with staring and glaring the private parts and in the spur of the moment they would touch you when you are busy with some other class chores. 
We live in a society where male is trained as the dominant individual of the society and in order to maintain that stature he believes in subsiding the female genders.

The way he used to talk to me or treat me used to make me feel weak and reinforce that I am a woman whom he can always hurt. He used to crush my selfrespect under his male ego and male chauvinism.

Miss. HH, Interview from field data

As Miss $\mathrm{HH}$ shares that she was feeling threatened and weak due to the immense masculinity and ego. She was losing her esteem every time this particular student used to negate her directions.

\section{Elements of Sexual Harassment}

While reading and re-reading, and during categorization of the interviewed transcripts, I came up with the following themes which can be termed as the elements of sexual harassment which according to the teachers are considered as physical, verbal and gestural assault. These elements are impropriety towards female gender considering them weak and vulnerable, trying to threated them and frighten them. Sexual objectification, i.e. considering women as sexual object to be utilized for satisfying the sexual urge. Physical advancement and direct assault by grouping up, deliberately coming to the close proximity to touch the private parts, finding ways to physically molest the teacher are also one of the elements of sexual harassment as pointed out by the interviewees. Apart from physical assault, there are many ways of verbal assault as well which implies the same meaning of sexual harassment as extracted for other elements. These verbal assault range from metaphoric comments to whistles and in worst case use of vulgar language. Apart from verbal and physical assault, which have already been mentioned by many theorists, a new form of harassment is also identified which is gestural harassment. Making gestures and faces which are unwelcoming and sexual in nature, like making faces, moaning in the class, grinning and double meaning smiles while playing with their private parts. Teachers also identified gazing and staring their private parts as a severe and pervasive sexually harassing action which makes the teachers uncomfortable and sexually conscious. Some students tend to send obscene and sexual contents over social websites and social chat forum to the teachers. Such contents also include editing the picture of the teacher as a porn star or any other intimate not acceptable positions.

\section{Essence of Sexual Harassment}

\section{Response/Reaction after Being Faced with Sexually Harassing Incident}

Being in a situation is hard to coop and difficult to digest for a teacher who is not expecting such sickening behaviour. Incidents like approaching and physically assaulting 
teachers are hard for them to digest and accept. They don't only get ashamed, but their esteem and self-respect tore into parts after being faced an encounter.

At $P$ college, after being touched and assaulted by one of my own students I was numb. I didn't know what to do and what to say, I just asked all the students around to go away. I dint go to the college on the next day. I was not gathering enough courage to even see myself in the mirror. Since that day onwards, my relation with my students changed. I stopped being friendly with them and kept them not only at a distance but also at par.

Miss HH, Interview from field data

As soon as I registered that they were moans of a porn movie I was shocked and moved. I just did not know what to do. I could not move from my lecture board. I was frozen and my heart was pounding. These voices in my head were mounting. I was in an emotional roller coaster ride, I wanted to burst into tears and run away from the class or may be college. Voices in my head were telling me kill this student, beat him to hell teach him a lesson.

Miss RY, Interview from field data

Things started to become worst when they started watching porn. My entire body was shaking and I was completely dazed. Bombs exploding in my brain and a chaos in the muscles.

Miss SN, Interview from field data

A relation between a teacher and a student is considered and seen as a respectful and courteous. In the moment of sheer disrespect, the teachers did not know how to respond to it. They felt helpless and disrespected at the same time. They did not know how to respond to it initially as it was completely an unexpected action. And the worst of the situations is when such students explicitly physically, verbally or through their gestures assault them.

These were the kids, in whose eyes I only used to see respect and honour.

Miss $H H$, Interview from field data

He would sit at the back, making dirty faces and vulgar gestures, expecting me to react. I cannot forget the disgustingly lustful eyes and the way it used to pierce through my clothes as if I am standing naked posing in a brothel.

Miss RY, Interview from field data At first I thought it was some carton or bag which students were carrying. But after some moments that touch converted into a whole grip on my lower back.

Miss NO, Interview from field data

These were not just normal students, they are socially charged and ethically lowered students who drive pleasure in physically assaulting the teachers. The cherish their deeds 
and drive gratification from such actions. There can be many reasons behind such a low thinking and action but it leaves lasting impression on the teachers. These teachers, who were devoted and dedicated to the students, changed the way they used to be with their kids and transformed into less courteous person. The start living in a state of constant depression, threat and fear of being molested again by any of their students. The low selfesteem and aggression couple up to cause demotivation and ends up either in teaching leaving the school/college or becoming a psychological patient.

\section{Sharing the Incident}

Almost all the respondents replied in negative when asked this question. It was for them a matter of personal image, social image, reputation, social unacceptability of possibility of any such incident, and fear of being sacked kept them quiet. The did not want to be a talk of the town.

Because management would have held me responsible for being care free and raised questions on my character rather finding the student.

Miss $\mathrm{HH}$, Interview from field data

I didn't share this event as well with any of my friend, family or colleagues in a fear of being misunderstood. I didn't want to sound sickened and disgusted.

Miss $R Y$, Interview from field data

I would not have been allowed to even see the face of the road after hearing this story or even any part of it. I do not have friends here.

Miss SN, Interview from field data

We live in a society where women are objectified and personified as an object of sex and then blamed as well for any misdeed conducted by male gender. I am not trying to sound like a feminist, rather it is a matter of fact that this very way of thinking has been embedded deep into our society which leverages men to do what they like, because at the end of the day, they know that even if reported, a women's respect would only be at stake. This fear of being not understood and being blamed leads to the decision of avoiding such situation which in turn magnifies into far greater obscenities.

\section{Steps/Measures Taken to Avoid Such a Situation}

Most of the incidents of such sort go unreported. This is primarily because of the personal image of the teacher being at stake. Most of the teachers at such level are unmarried and they have fear of getting bad name attached with them. Even reporting to higher management would not be fruitful as most of the school or colleges which have such disciplinary concerns, are mere business points. The management usually do not take any 
concrete steps and only tells the teacher to be more vigilant. However, taking a step on your own of counselling or getting to know the student can help.

I came up with the idea of talking to them. I thought of counselling them and get to know the deeper causes behind such behaviour of these students.

Miss SN, Interview from field data

This strategy of dealing with mischievous and ill-behaved students is only fruitful when the person is strong and being strong is the only option they have. As done by Miss SN, she tried to not only talk to them but getting a deeper understanding of the reasons behind their such actions. She faced a lot of problem initially, but at the end of the day managed to pull of the goodness in them. Another step that can be ideal is to call the parents and have a conversation with them. This was done by Miss HH, when she called the parents of the student. Parents took a quick notice of the situation and ensured it to her that nothing of such sort will ever happen. Miss HH reported that it worked.

I ignored it initially but then reported it to my Principal who without a second thought called his parents.

Miss HH, Interview from field data

Another way to deal with such situation that teachers have figured out is complete ignorance. They believe that ignoring is the best policy to deal with such a student. In order to preserve self-image, they limit their bonds with students and keep them at par. They fear that reporting will only make things bad for them and can have bad consequences in their later life. And as soon as they get the chance to switch they leave the job and switch to another college or school.

\section{Reason Behind Sexually Harassing Conduct}

In order to understand the true essence of sexually harassing actions of the students directed towards their faculty/teachers, it is necessary to dissect the reasons behind this behaviour. Such an action/gesture is a combination of many socio-cultural aspects which jumble up to develop a sense of perverseness. With respect to the enliven experience, the teachers interviewed believed that this behaviour is due to mismanagement of the authorities, family background and negligence, personal past experiences, media and internet, biological urge and masculinity, and last but not the least social gathering of the student and his age.

Due to sheer lack of attention from the family, kids fall into clinches of social circles and internet/social media. The negligence from parents coupled with free access to all the luxuries of life without any proper check and balance leads to searching of care and love outside the family. This makes kids vulnerable to many bad habits like smoking, hooking 
up, pornography, unhealthy life style and others. Misbehaving or socially unacceptable conduct is also primarily caused by lack of due attention and care from family.

Parents forget the reason they are working so hard day and night

Miss RY, Interview from field data

Parents usually don't train their kids to respect their teachers nowadays. Parents facilitate their kids through all the means, i.e. financially, monetarily and provide them with everything

Miss Sid, Interview from field data

Media is playing a negative role in it as well.

Miss Sid, Interview from field data

Moreover, these grown adults have biological urges and developments which are often neglected in our schools even who find it a taboo to give students a sex education class. Also parents don't try to tame or shape the masculinity in their sons which turns out to be a frustration for the students and flushes out in the name of adulthood.

The poor management and lenient management style is also an emergent theme. Every male student has biological urges and masculinity issues throughout the world, but such incidents are common in colleges or school which lack a disciplinary system and where management only ask the teachers to avoid the situation. Such schools/colleges do not realise the importance of power and its exercise to keep the students tamed. They consider students as client while teacher are tools to earn money from them. The objectification of teachers on the management on higher level ends up sexual objectification of teachers in the class. That is why such schools have high turn-over rate.

\section{Discussion}

Sexual harassment is not a new phenomenon; it has been under study since more than 2 decades where tons of papers have been produced. However, sexual harassment of teachers by the hands of students of secondary and higher secondary schools, during a formal educational environment has not gained much theoretical importance in scholarly circles. Teachers define harassment as an unwanted sexual advancement through gestures, verbal and physical assault which ripens the atmosphere of sexual consciousness, undesired and unwelcoming shaming, humiliation, indecency, threat, imposition, coercion and seductive behaviours. Dobry, (2013) describe such behaviour causes the recipient to undergo a state of trauma. The traumatized individual becomes less tolerant and sympathetic. Defining further, Dobry (2014), the harassing actions and gestures are at times the revenge of the incidents the recipients have gone through in the past. In extreme cases, where students have experienced sexual torture or teasing, turns non- 
sympathetic to the society and enters in a denial phase where he challenges the person in authority and advances to torture them in similar hurtful behaviour. Masten (2014), states that such behaviour is a resultant of confusion and muddle of feelings, developed from social interactions through different online and other forums. Young males, with inability to express their feelings and sexual attractions lead to harassing activities. However, my findings donot completely comply with this definition. The pathological view lacks an important aspect where students drive pleasure in teasing and torturing someone as part of the societal upbringing. Many times it is reported that socio-cultural system has adverse effects on the behaviour of the individuals. These students are no different. The observational learning from their social environment develops an impulse of teasing and joshing. Abuse of power or power theory has its importance as well. Going through the analysis, one of the emerging reason for such sexual acts as ascribed by the victim teachers, power and authority shift plays vital role in harassment of the female teachers. The school/college authority loses their exercisable authority to comfort the "customers/clients", giving more power and authority to students then the teachers. The students misuse the power and threaten and abuse the situation of the teacher. The situational benefit is usually in the form of sexual abuse and torture where students exhibit sexual coercion and imposition. Free access to internet and availability of means to watch porn and sexual scripts is also debatable to be one of the reasons of such a conduct. Viewing pornography increases problematic conducts and attitudes such as sexual objectification of women (Bridges, Bergner \&Hesson-McInnis, 2003). The misdeeds cause dissatisfaction and demotivation among teachers and in worst cases leads to loss of self-respect and self-confidence leaving the teachers traumatized, disturbed, shocked and anger. The female teachers, in order to protect their social and family image, do not report such incidents. These students tend to get encouraged with this ignorance and their deeds magnify many folds. The teachers, who raise themselves beyond such societal and family pressure, and report the incidents to the high ups or make a move on their own to deal with the situation do not get to face any such situation from the same student.

\section{Trustworthiness}

For credibility of the study and to ensure that the researcher is capturing the same essence as said and transcribed a peer review was conducted where the transcriptions, codes and thematic analysis were shared with qualified researcher. The researcher confirmed that the study was conducted in a systematic manner and conclusions drawn are also reasonable. For theoretical generalizability, purposefully samples were selected who were not only willing to share their enliven experiences but also had the ability to well transform them into words. From the process of transcription and till reporting the conclusion, all the documents collected and yielded are trackable for a complete audit trail. The topic under study was of sensitive nature and required the researcher to be 
completely free from all the bias due to the gender of the researcher. To address the reflexivity, the role of researcher has been added in the introduction part which summarizes the intent and his non-bias nature and non-empathized nature towards the study under consideration.

\section{Conclusions}

To achieve the purpose of the study three questions were devised and addressed. The first research question has been answered by providing the ascribed definition of sexual harassment based on the enliven experience of the teachers. The defining terms were based on five defining actions and gestures which combine to induce a feeling of being harassed in an educational environment. These themes were impropriety towards female gender, sexual coercion, sexual imposition, gestural misconduct and sexual objectification.

The second research question was addressed emerging themes of numbness, anger and shock which made the teachers frozen or immovable for some time. The teachers reported to have a disgusted feel along with shaming and humiliation which led to demotivation and in worst case they changed their behaviour with all the students for the rest of their lives. The teachers stated that weak management of the institution, family negligence and undue leniency, lack of check and balance, social gathering, media, pathological issues, genderality and un-channelized biological developments are the reasons behind the sexually harassing behaviours of the students.

To address the third question that is the elements of the sexual harassment that emerged as major themes were direct impositioning, verbal pasting, playing or sending obscene materials, and gazing and commenting on private parts of the teachers during school hours.

\section{Recommendations}

The research under study covers the breadth of the issue at hand and will serve as a point of start in realizing the theoretically neglected form of sexual harassment which is causing a jolt to the educational integrity. This is one of the main reason behind the high teacher turnover rate and in worst cases ends up the teacher leaving the education industry. In the context of Pakistan, education is one of the major issues which needs to be dealt with seriousness. A deaf ear to such issues may lead to a complete dearth of competent and dedicated teachers. Therefore, depth of the issue has to be understood with focus on each element identified in the paper and the causing reasons behind them. 


\section{Reference}

Bourne, P. A., Hudson-Davis, A., Sharpe-Pryce, C., Francis, C., Solan, I., \& Nelson, S. (2015). Homicide, Rape and Carnal Abuse in Jamaica, 1970-2013: The New Health Pandemics. International Journal of Emergency Mental Health and Human Resilience, vol.17:2, pp. 588-597.

Braithwaite, S. R., Coulson, G., Keddington, K., \& Fincham, F. D. (2015). The Influence of Pornography on Sexual Scripts and Hooking Up among Emerging Adults in College. Archives of Sexual Behavior, vol.44:1, pp.111-123.

Bridges, A. J., Bergner, R. M. \&Hesson-McInnis, M. (2003). Romantic Partners' Use of Pornography: Its Significance for Women. Journal of Sex and Marital Therapy. vol.29:1, pp.1-14.

Bridges, A. J., Wosnitzer, R., Scharrer, E., Sun,C. \& Liberman, R. (2010). Aggression and Sexual Behavior in Best-Selling Pornography Videos: A Content Analysis Update. Violence Against Women. vol.16:10, pp. 1065-1085.

Brosius, H., Weaver, J. B. \& Staab, J. F. (1993). Exploring the Social and Sexual 'reality' of Contemporary Pornography. Journal of Sex Research. vol. 30:2, pp.161-170.

Brown, J. D. \& L'Engle, K. L. (2009). X-Rated: Sexual Attitudes and Behaviours Associated with U.S. Early Adolescents' Exposure to Sexually Explicit Media. Communication Research. vol.36:1, pp.129-151.

Butler, J. (2002). Gender Trouble. New York: Routledge.

Corbett, K. \& Gentry, C. S. (1993). Sexual Harassment in High School. Youth and Society, vol.25:1, pp.93-103.

Dobry, Y., Braquehais, M. D., \& Sher, L. (2013). Bullying, psychiatric pathology and suicidal behavior. International Journal of Adolescent Medicine and Health. vol.25:3, pp. 295-299.

Gelfand, M. J., Fitzgerald, L. F. \& Drasgow, F. (1995). The Structure of Sexual Harassment: A Confirmatory Analysis Across Cultures and Settings. Journal of Vocational Behavior, vol.47:2, pp.164-177. 
Keddie, A. (2007). Issues of Power, Masculinity, and Gender Justice: Sally's Story of Teaching Boys. Discourse: Studies in the Cultural Politics of Education, vol.28:1, pp.21-35.

Keddie, A. \& Mills, M. (2008). Teaching Boys: Developing Classroom Practices that Work. Primary \& Middle Years Educator, vol.6:1, pp.11-15.

Lambert, N. M., Negash, S., Stillman, T.F., Olmstead, S.B. \& Fincham, F.D. (2012). A Love that Doesn't Last: Pornography Consumption and Weakened Commitment to one's Romantic Partner. Journal of Social and Clinical Psychology, vol.31:4, pp.410-438.

Lahelma, E., Palmu, T. \& Gordon, T. (2000). Intersecting Power Relations in Teachers' Experiences of being Sexualized or Harassed by Students. Sexualities, vol.3:4, pp.463-481.

Lester, J. (Ed.). (2013). Workplace Bullying in Higher Education. New York, USA: Routledge.

Lindsey, L. L. (2015). Gender Roles: A Sociological Perspective. New York, USA: Routledge.

MacKinnon, C. A. (2015). In Their Hands: Restoring Institutional Liability for Sexual Harassment in Education. Yale Law Journal, vol.125:7, pp. 2038-2105.

Martino, W., \& Pallotta-Chiarolli, M. (2003). So What's A Boy?: Addresing Issues of Masculinity and Schooling. United Kingdom: Open University Press

Martino, W., \& Pallotta-Chiarolli, M. (2005). Being normal is the only way to be: Adolescent perspectives on gender and school. Sydney, Australia: UNSW Press.

Magee, J. C. \& Smith, P. K. (2013). The Social Distance: Theory of Power. Personality and Social Psychology Review, vol.17:2, pp.158-186.

Masten, A. S. (2014). Global Perspectives on Resilience in Children and Youth. Child Development, vol.85:1, pp.6-20.

Mitchell, K. J., Ybarra, M. L. \& Korchmaros, J. D. (2014). Sexual Harassment among Adolescents of Different Sexual Orientations and Gender Identities. Child abuse \& Neglect, vol.38:2, pp.280-295. 
Mubin, M., Vohra, M., Ijaz, S., Rafique, M. \& Hassan, T. (2014). Cultural Mapping and Its Ascertainment: A Case Study of PTCL. European Journal of Business and Management, vol.6:14, pp.83-94.

Nøttestad, J. A., Øverland, S. \& Hald, G. M. (2010). Fremmer pornografi voldsunderstøttende holdninger og seksuell aggresjon mot kvinner? Tidsskrift for Norsk Psykologforening, vol.47:12, pp. 1112-1114.

Okin, S. M. (1989). Justice, Gender and the Family, vol.171. New York: Basic Books.

Pateman, C. (2016). Sexual Contract. In The Wiley Blackwell Encyclopedia of Gender and Sexuality Studies (eds A. Wong, M. Wickramasinghe, r. hoogland and N. A. Naples). doi:10.1002/9781118663219.wbegss468

Pateman, C. (2005). Equality, difference, subordination: the politics of motherhood and women's citizenship. In G. Bock \& S. James (Eds.), Beyond equality and difference (1st ed., pp. 22-35). Londong: Routledge.

Polkinghorne D. E. (1989) Phenomenological Research Methods. In: Valle R.S., Halling S. (eds) Existential-Phenomenological Perspectives in Psychology. New York: Plenum Press

Pryor, J. B., \& Whalen, N. J. (1997). A typology of sexual harassment: Characteristics of harassers and the social circumstances under which sexual harassment occurs. In W. O'Donohue (Ed.), Sexual harassment: Theory, research, and treatment (pp. 129-151). Needham Heights, MA, US: Allyn \& Bacon.

Robinson, K. (2000). Great Tits, Miss!' The Silencing of Male Students' Sexual Harassment of Female Teachers in Secondary Schools: A Focus on Gendered Authority. Discourse, vol.21:1, pp.75-90.

Stein, N. \& Sjostrom, L. (1994). Flirting or Hurting? A Teacher's Guide on Student-toStudent Sexual Harassment in Schools (Grades 6 through 12). Washington, USA: NEA Professional Library.

Silin, J. (1997). The Pervert in the Classroom. In TOBIN J. (Ed.), Making a Place for Pleasure in Early Childhood Education (pp. 214-234). Yale University Press. Retrieved from http://www.jstor.org/stable/j.ctt1bh4c70.10 
Stein, N. D., Marshall, N. L., \& Tropp, L. R. (1993). Secrets in Public: Sexual Harassment in our Schools. Wellesley College 106 Central Street, Wellesley, MA 02481: Wellesley Centers for Women

Timmerman, G. (2003). Sexual Harassment of Adolescents Perpetrated by Teachers and by Peers: An Exploration of the Dynamics of Power, Culture and Gender in Secondary Schools. Sex Roles, vol.48:5-6, pp.231-244.

Akbar, W., et al (2014). Urdu Medium Intermediaries Issues Getting Higher Education in English Medium Institutions: Evidence from Pakistan, Journal of Education and Practice, vol.5:13, pp.37-49.

Dr. Zaeema Asrar is Incharge in the Department of Commerce, University of Karachi.

Syed Waqas Hussain is Ph.D Scholar in the Department of Management Sciences, SZABIST, Karachi.

Muhammad Mubeen is Research Scholar in the Department of Management, Bilkent University, Turkey. 